\title{
On the vulnerability of river levees induced by seepage
}

\author{
G. Michelazzo, E. Paris and L. Solari \\ Department of Civil and Environmental Engineering, University of Florence, Firenze, Italy
}

\author{
Correspondence \\ Luca Solari, Department of Civil and \\ Environmental Engineering, University of \\ Florence, Via di S. Marta 3, 50139 Firenze, \\ Italy \\ Email: luca.solari@unifi.it
}

DOI: $10.1111 / \mathrm{jfr} 3.12261$

Key words

Flood; hazard maps; levee failure; seepage; vulnerability.

\begin{abstract}
Seepage through earthen levees is a mechanism often observed during floods and can lead to levee failure if combined with internal erosion. This notwithstanding, hazard maps for levee failure are often elaborated solely considering the mechanism of overtopping. In this work, the assessment of levee vulnerability relative to seepage is investigated by considering the characteristic time scales of the phenomena and the main factors upon which they depend. In particular, the persistence of hydrological load is compared with the critical time of seepage associated to the emergence of the phreatic line along the landside of levees. The results can easily be applied to long river reaches, elaborating of through seepage-hazard maps and locating the levees that are more vulnerable to seepage failure.
\end{abstract}

\section{Introduction}

Flooding is a natural hazard which probably has the highest occurrence in time and space across the world, every year causing considerable damage in terms of loss of life and property (Loat, 2009). In European countries alone, more than 7000 people have died due to flood disasters since 1926 (Guha-Sapir et al., 2014).

Although the primary function of a river levee is to retain water so that the surrounding lands are protected from flooding, a levee can fail by means of hydraulic and/or structural mechanisms. The first failure mode occurs if water reaches protected lands by flowing over, through or under the levee body, whereas the latter is usually associated with the collapse of the levee structure and with the consequent breach and may be induced by several causes (e.g. river erosion, settlement, slope instability, earthquake, ...).

Overflowing and seepage are among the most frequent hydraulic causes that can initiate the breaching process of a levee (Horlacher et al., 2005; Nagy and Tòth, 2005; Nagy, 2006; Morris et al., 2007). While overflowing can lead a levee to breach because external erosion mechanisms take place, seepage of water through and under a levee during times of flood may become a matter of concern for the safety of a levee when internal erosion mechanisms occur (Ozkan, 2003). Indeed, seepage can induce the mobilisation of soil particles from the internal core of the levee or from the foundation layer. Whenever a levee is subjected to a differential hydrostatic head of water as a result of river stages higher than the surrounding land, seepage enters the pervious substratum through the bed of the river and through the riverside levee slope, and this creates a hydraulic gradient in the stratum under or through the levee. This gradient causes a flow of seepage which can weaken the levee structure if the hydrodynamic forces are strong enough to mobilise the soil particles: the migration of particles from the levee body outward is then induced by the pore water pressure and the interstitial flow of water.

Moreover, it is well known that high water levels against a levee for a long enough time period may cause the levee to become saturated and eventually to collapse. The presence of seepage flow is known to generate variations in the pore water pressure which may induce internal erosion and affect the embankment stability (Staiano et al., 2001; Fox et al., 2006; Vorogushyn et al., 2009; Nardi et al., 2012).

In recent years, the number of levee failures increased dramatically in several Italian embanked rivers with catchment areas ranging from a few dozen to more than $1500 \mathrm{~km}^{2}$, meaning that this problem is now of critical importance at a national scale (Barbetta et al., 2015). Most of such levee collapses had in common a similar failure mechanism of internal erosion without overtopping, as, for instance the levee failures of the river Po (Mazzoleni et al., 2014) and the river Serchio (Cosanti et al., 2011). A recent example of this kind of levee failure occurred on the levee of the river Ombrone Pistoiese, in central Italy, during the flood event of 25 December 2009, as depicted in Figure 1. These events prompt the reconsideration of the risk associated with inundation scenarios, as the probability of levee 


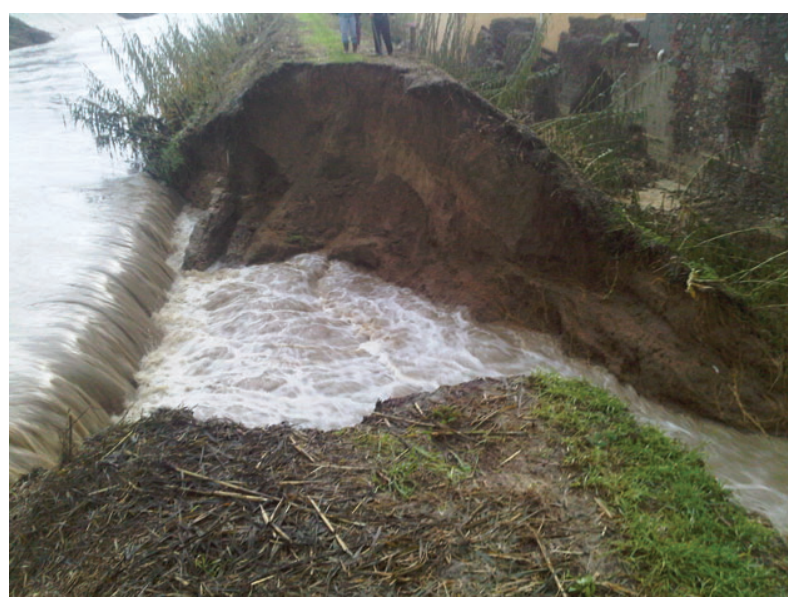

Figure 1 Levee failure in the Ombrone Pistoiese river (Tuscany, Italy) induced by seepage during the flood event of 25 December 2009. Photo by Land Reclamation Authority of Ombrone River.

failure due to its collapse may be even greater than that of overtopping (Bogdanowicz et al., 2014).

Recently, Camici et al. (2015) investigated the levee body vulnerability using the equation for seepage flow proposed by Marchi (1961) to develop a procedure based on a vulnerability index related to the probability of occurrence of levee piping. They applied the proposed procedure to the levee failure of the river Foenna (central Italy) that occurred in 2006. Their procedure takes into account the uncertainty of hydraulic parameters and forecasts the vulnerability to seepage in terms of probability. Unlike this study, they did not focus explicitly on the time scale of the seepage phenomenon, on the linkage with the hydrological persistence of the flood hydrograph or on the implications for the elaboration of seepage-hazard maps.

This study aims to investigate the relative vulnerability of earthen levees due to a through-seepage flow on the basis of the characteristic time scales related to the mechanisms of soil saturation and peak flood duration. Following the approach by Camici et al. (2015), the analysis is based on the equation for seepage flow proposed by Marchi (1961) to predict the levee critical conditions associated with the main embankment characteristics and with the flood hydrograph. The Green-Ampt method (Green and Ampt, 1911) for horizontal seepage flow has also been used for a comparison as proposed by Pistocchi et al. (2004). Sensitivity of the model results on the characteristic parameters (porosity, hydraulic conductivity as well as position of the undisturbed water table) has been also assessed. The results are applied here to a reach of the river Ombrone Pistoiese in Tuscany (Italy) to obtain seepage-hazard maps, which can be considered as a fundamental tool for flood-risk assessment.

\section{Assessment of levee vulnerability to seepage}

The seepage through or under the levee body is the main factor inherent to the development of internal erosion, which can occur in the form of several mechanisms, such as piping, concentrated erosion, contact erosion and suffusion (CIRIA et al., 2013). Each process differs from the other in terms of the mode of mobilisation of soil particles, that is, particle-by-particle erosion for piping, contact erosion at the boundary between fine and coarse soils, and particle or mass erosion of finer particles for suffusion, and each process is governed by seepage: as the soil is washed away, the seepage flow increases and, consequently, a larger erosive action is exerted on soil particles. In the case of piping, the erosion initiates if the phreatic front reaches the landward surface of the levee and the hydraulic gradient exceeds the critical gradient, and there is a backward development where soil particles are moved out until a sort of pipe is created within the levee structure. Such backward erosion continues towards the riverside and this process can weaken the levee structure until the soil above the pipe collapses and a breach occurs. Several contributions in understanding the piping mechanism are available in literature (Sherard et al., 1963; Van Zyl and Harr, 1981; Foster et al., 2000; Mohamed et al., 2002; Fell and Wan, 2005; Saucier et al., 2009).

As for the other erosion modes, seepage is necessary for the piping development and, even though not sufficient by itself to trigger internal erosion, it is the governing phenomenon. Vorogushyn et al. (2009) investigated the mechanisms of levee collapse and outlined the seepage phenomenon as a vulnerability issue associated with hydrological load persistence and intensity.

As a matter of fact, a well-designed levee should contain the phreatic line within its body and the possibility of seepage flow rate outing from the levee should be avoided or, at least, controlled and limited to small values. The condition in which the phreatic line reaches the protected side is in itself a hydraulic failure of the levee performance and represents a dangerous situation that affects the levee reliability, as it may lead to consequent critical conditions for soil particles erosion. The importance of this condition is also stated by Camici et al. (2015) and it is recognised in real cases, as, for instance, the levee breach of the river Serchio that was triggered by the emergence of seepage flow on the landside slope during the 2009 event (Bonanni et al., 2010; Cosanti et al., 2011).

The propensity of a levee to undergo seepage processes without overtopping, that is its seepage vulnerability, is recognised here as a key point to assess the reliability of the flood defence system; the proposed approach aims to relate such vulnerability to the comparison between the time scales of the seepage process and of the persistence of flood 
levels in the river. The time scale of the through-seepage process associated with the state of the phreatic line reaching the landward surface is addressed as a typical condition that may lead to successive failures as stated previously.

\section{Analytical models}

A simplified physics-based procedure is proposed by means of a schematic analysis of the seepage through the levee body driven by the persistence of a flood water level in the river.

The main assumptions of the proposed methodology are:

- homogenous and isotropic geotechnical properties of the soil composing both the levee body and the foundation in terms of hydraulic conductivity $k$ and porosity $n$;

- trapezoidal shape of the cross-section of the levee.

A sketch of the investigated problem is given in Figure 2; the six points $\mathrm{P}_{1}-\mathrm{P}_{6}$ define the main geometrical features in terms of: thalweg $\left(\mathrm{P}_{1}\right)$, riverside bank $\left(\mathrm{P}_{2}-\mathrm{P}_{3}\right)$, toe of riverside slope $\left(\mathrm{P}_{3}\right)$, levee crest $\left(\mathrm{P}_{4}-\mathrm{P}_{5}\right)$ and toe of landside slope $\left(\mathrm{P}_{6}\right)$.

The critical condition is found when the phreatic line reaches the landside slope of the levee cross-section (see Figure 2). As introduced previously, this situation is representative of internal conditions that make the levee body prone to internal erosion mechanisms, such as piping, which may quickly develop towards a full breach in the levee system.

The proposed methodology is based on the comparison between the persistence of the river water level and the time required for the phreatic line to reach the landside slope of the levee. This latter time is denoted as 'critical time' $T_{\text {cr }}$ and it is determined by means of two different analytical models that have been found to fit the aim of the problem in an expeditious procedure: Marchi's (1961) and modified Green-Ampt's (Pistocchi et al., 2004) models.

\section{Marchi's model}

In this case, the definition of the phreatic line and the critical time for the occurrence of its emergence at the landside slope is based on the model proposed by Marchi (1957, 1961). This model provides an analytical expression for the phreatic line through the levee body that is given by the envelope of the seepage front forced by the river water level.

Marchi's model combines the continuity and Darcy's equations; these are simplified by taking into account some further assumptions in addition to the already stated geotechnical and geometrical schematisation of the levee body:

- the capillarity fringe is neglected;

- Dupuit's hypothesis holds;

- seepage is simulated as a plane flow;

- the seepage depth is small compared with the thickness of the aquifer;

- the levee soil on the riverside slope and under the river water level is not included in the spatial domain.

The level of the undisturbed water table is taken as the downstream boundary condition, which is asymptotically reached by the phreatic line at a theoretical 'infinite' distance from the riverside slope. The spatial domain of resolution starts from the vertical plane passing through the intersection between the imposed river water level and the riverside slope (point $\mathrm{P}_{4}$ in Figure 3): this may not be fully consistent with real situations, since seepage first fills the soil strata nearest to the riverside.

The sketch in Figure 3 depicts the schematisation of the levee geometry and the variables that are relevant in the application of Marchi's model. In particular, the following quantities are referred to the $x-y$ axes centred in $\mathrm{P}_{3}$ :

- $h_{0}=$ flood level of the river;

- $y_{\text {thalweg }}=$ level of the river thalweg;

- $H_{\mathrm{LR}}=$ height of levee at the riverside;

- $H_{\mathrm{RF}}=$ level of the undisturbed water table;

- $h=$ elevation of the phreatic line;

- $x_{\text {in }}=$ value of the horizontal coordinate $x$ that defines the vertical boundary of the spatial domain.

By taking into account a schematic rectangular flood hydrograph characterised by the duration $T$ and the flood level $h_{0}$, Marchi proposed a linearised analytical solution
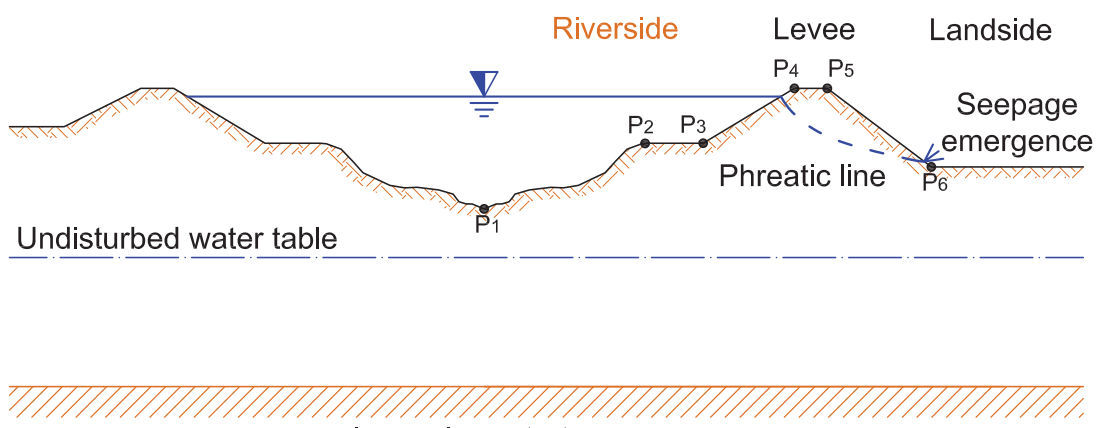

Impervious stratum

Figure 2 Sketch and notations for through-seepage failure analysis of a river levee. 


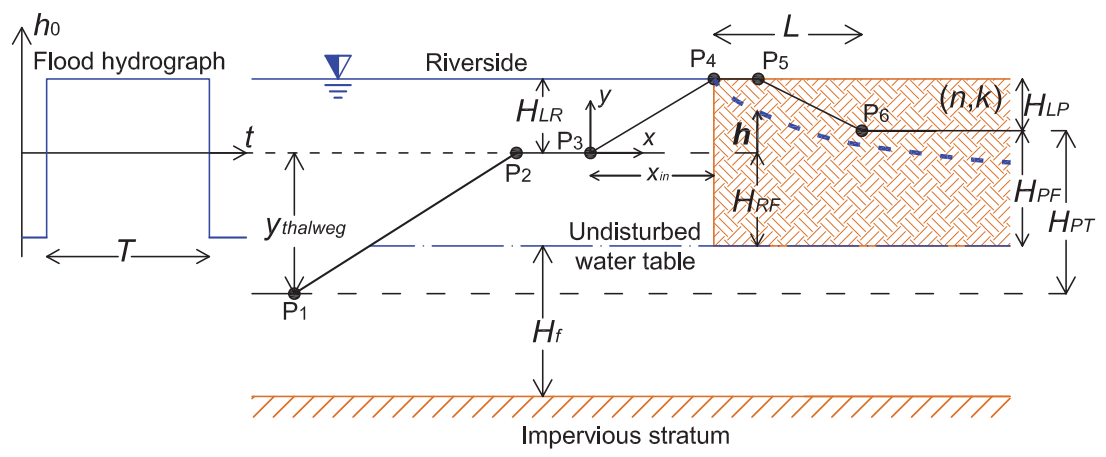

Figure 3 Relevant parameters used in the application of Marchi's model: the spatial domain of the problem is defined by the shaded area, the phreatic line is represented by the bold dashed line.

that was further simplified for the case of a deep phreatic aquifer (that is when $H_{\mathrm{f}}>L$, with $L=$ horizontal distance between $\mathrm{P}_{6}$ and $x_{\text {in }}$ and $H_{\mathrm{f}}=$ thickness of the aquifer):

$$
\begin{aligned}
\frac{h(x)+H_{\mathrm{RF}}}{h_{0}+H_{\mathrm{RF}}}= & \frac{2}{\pi} \operatorname{arctg} \frac{k T}{n \cdot\left(x-x_{\mathrm{in}}\right)} \text { valid for } x>x_{\mathrm{in}} \text { and } \\
& -H_{\mathrm{RF}}<y<H_{\mathrm{LR}}
\end{aligned}
$$

\section{Adaptation of Green-Ampt's model}

This model is based on the approach by Green and Ampt (1911) and is adapted to the case of a horizontal seepage flow. The model assumes that the infiltration takes place through the levee body along horizontal planes that are independent from each other. The location of the phreatic line is identified by coupling the continuity and Darcy's equations: the integration of the flood hydrograph at different levels $y$ provides the position of the seepage front through the levee (as depicted in Figure 4). In such a model, the capillarity action is neglected together with the interchanges of water flows along the vertical direction. This may be a questionable assumption since the real seepage process through a homogeneous and isotropic levee takes place as a phreatic front that is hydraulically connected along the vertical direction. However, the model solves for the phreatic line position within the entire levee body, so that the spatial domain matches the real geometry of the levee.

The sketch in Figure 4 depicts the schematisation of the levee geometry and the variables that are relevant in the application of Green-Ampt's model. In particular, the following quantities are referred to the $x-y$ axes centred in $\mathrm{P}_{3}$ :

- $h_{0}=$ flood level of the river;

- $y_{\text {thalweg }}=$ level of the river thalweg.

The formulation of this model reads:

$$
\left\{\begin{array}{l}
x_{\mathrm{GA}}(y)=\sqrt{\frac{2 k}{n} V(y)} \\
V(y)=\int_{t_{1}}^{t_{2}}\left[h_{0}(t)-y\right] \mathrm{dt}
\end{array}\right.
$$

where $x_{\mathrm{GA}}(y)$ is the horizontal distance between the phreatic line and the riverside levee slope at the level $y, V(y)$ is the volume of the flood hydrograph above the level $y$ and $t_{1}$ and $t_{2}$ are the time coordinates which define the duration $T$ of the flood level (i.e. $T=t_{2}-t_{1}$ ).

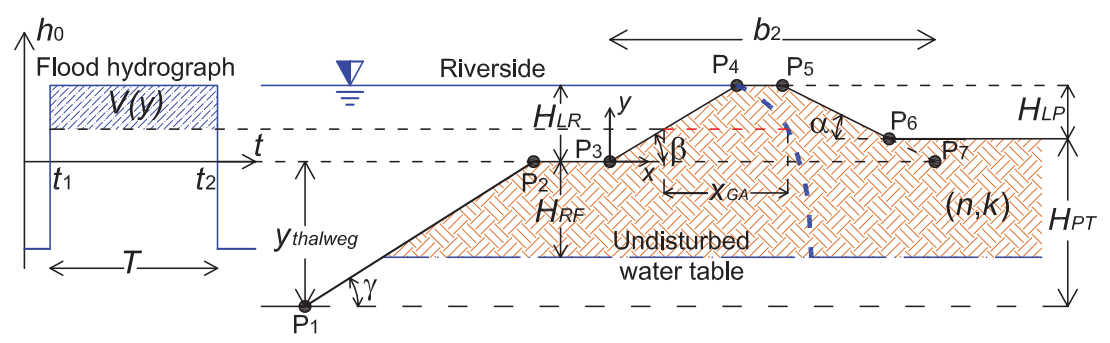

Impervious stratum

Figure 4 Relevant parameters used in the application of Green-Ampt's model: the spatial domain of the problem is defined by the shaded area, the phreatic line is represented by the bold dashed line. 


\section{Results and comparison}

The above models give a different prediction of the phreatic line position because they are based on quite different assumptions. At the same time, both models are useful tools for verifying the through-seepage process for a levee and, because of their different analytical formulations, they are appropriate for the detection of criticality conditions occurring at the lower or medium-higher zone of the landside slope of the levee. Pistocchi et al. (2004) used some models similar to those proposed in this paper to predict the phreatic line through the levee body: they demonstrated that the solution obtained by the envelope of the two models gives a good approximation of that predicted by a more detailed numerical model which solves the Richards' equation by means of a finite volume technique. In fact, Marchi's model tends to give reliable results for the seepage flow in the lower region of the levee body, whereas it underestimates the saturation line in the region near the levee crest where the adapted Green-Ampt's method appears to be more realistic. The comparison between the two proposed models allows one to evaluate a conservative prediction that can be implemented in a straightforward way for long reaches of embanked rivers.

In order to be able to compare the two models, they are applied to the standard river levee geometry illustrated in Figure 5 in the case of $k=10^{-4} \mathrm{~m} / \mathrm{s}$ and $n=0.3$. The solutions are plotted by considering a rectangular flood hydrograph with two different durations of the flood peak ( $T=5 \mathrm{~h}$ and $T=15 \mathrm{~h})$.

Results in Figure 5 show that the predicted phreatic line changes significantly between the models. In particular, in Marchi's model, the lines start at the river side of the levee crest (point $\mathrm{P}_{4}$ ) and gradually decrease their elevation until asymptotically reaching the undisturbed water table level;

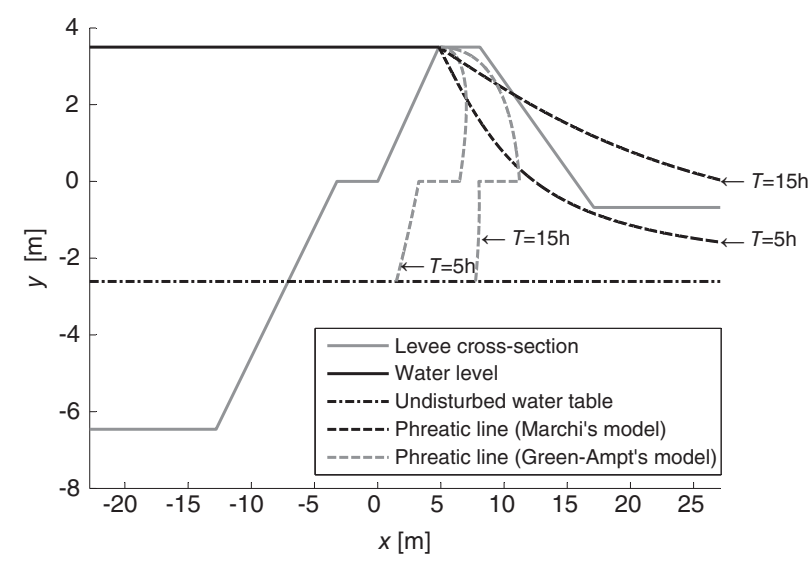

Figure 5 Results and comparison between Marchi's and GreenAmpt's models for a standard levee geometry. whereas the Green-Ampt's solution starts at the riverside slope and it is not affected by the undisturbed water table level in accordance with the assumption that the seepage flow is simulated along independent horizontal strips. Importantly, the first model predicts the emergence of the phreatic line at the landside slope toe, whereas the possible occurrence of the seepage on the middle-high zone of the landside slope is taken into account by the second model. The emergence of the phreatic line either at the levee toe or at higher elevations along the levee slope depends on the levee geometry.

The critical time $T_{\mathrm{cr}}$ for the seepage to reach the landside slope differs in the two models according to the geometry of the levee cross-section and to the undisturbed water table level. Following the present methodology, the envelope of the two seepage lines is used to obtain the minimum predicted time for that critical condition.

The models are implemented in order to find the critical combinations of river water level and its persistence for which the levee body is unable to contain the phreatic lines. For given levee geometric and geotechnical characteristics, there is a critical time $T_{\text {cr }}$ for which the flood water level $h_{0}$ lasts enough to make the phreatic line reach the landside slope. The emergence of the phreatic line can occur either in the upper or lower part on the landside slope according to the envelope of the two models. Such combinations define a curve $T_{\text {cr }}\left(h_{\text {norm }}\right)$ that divides the graph $\left(h_{\text {norm }} ; T\right)$ into two zones, as depicted by Figure 6 for the levee in Figure 5 (where $h_{\text {norm }}=\left[h_{0}-\left(y_{\mathrm{P} 6}-y_{\mathrm{P} 3}\right)\right] / H_{\mathrm{LP}}$ is the river water level $h_{0}$ referred to the landside elevation $\mathrm{P}_{6}$ and normalised by the landside levee height $H_{\mathrm{LP}}$ ):

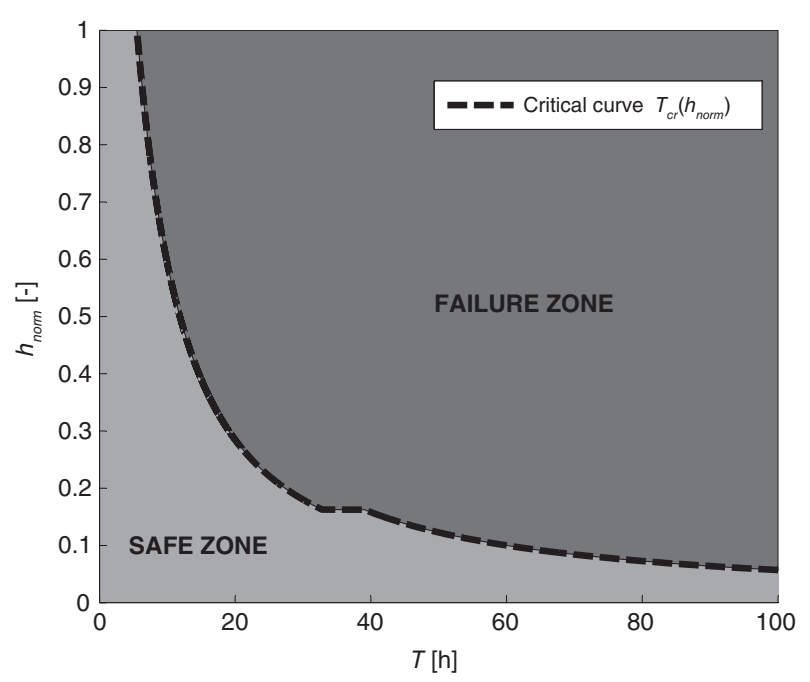

Figure 6 Curve $T_{\text {cr }}\left(h_{\text {norm }}\right)$ of critical combinations $\left(h_{\text {normi }} T\right)$ according to the envelope of the two seepage models for the levee of Figure 5; where $h_{\text {norm }}=\left[h_{0}-\left(y_{\mathrm{P} 6}-y_{\mathrm{P} 3}\right)\right] / H_{\mathrm{LP}}$. 
1. 'Safe zone', in which the combinations $\left(h_{\text {norm }} ; T\right)$ are below the critical curve and the phreatic line is not expected to reach the landside slope;

2. 'Failure zone', in which the combinations $\left(h_{\text {norm }} ; T\right)$ are above the critical curve and the phreatic line is expected to reach the landside slope and to induce possible failure mechanisms in the levee body.

The critical curve of Figure 6 is represented by normalising the hydraulic head $h_{0}$ by the levee height over the protected side: this choice provides a better understanding of the critical curve trend which has a minimum when the water level is at the levee crest (i.e. $h_{\text {norm }}=1$ ) and decreases towards an horizontal asymptote that is reached when water level approaches the protected side (i.e. $h_{\text {norm }} \rightarrow 0$ ). For instance, $h_{\text {norm }}$ for the levee and the flood level of Figure 5 is calculated as follows: $h_{0}=y_{\mathrm{P} 5}=3.5 \mathrm{~m}, y_{\mathrm{P} 6}=$ $-0.68 \mathrm{~m}, y_{\mathrm{P} 3}=0, H_{\mathrm{LP}}=y_{\mathrm{P} 5}-y_{\mathrm{P} 6}=4.18 \mathrm{~m}$, and results as $h_{\text {norm }}=[3.5-(-0.68-0)] / 4.18=1$.

\section{Sensitivity of the critical curve to the models' parameters}

The seepage process is known to be highly dependent on the geotechnical properties of the porous medium and it is of interest to analyse the sensitivity of the adopted models to each of the involved parameters.

In particular, the critical curve $T_{\text {cr }}\left(h_{\text {norm }}\right)$ can be determined according to different scenarios of porosity $n$ and hydraulic conductivity $k$. Figure 7(a) and (b) show how the critical curve is modified for different values respectively of $n$ and of $k$ and the same levee geometry: it is evident that shorter critical times are expected for decreasing $n$ and increasing $k$. As the hydraulic conductivity can range between orders of magnitude, it becomes the most important geotechnical parameter affecting the seepage time.

Moreover, a similar sensitivity analysis is performed for variations of the level of the undisturbed water table as shown in Figure 7(c). The water table level affects the phreatic line only in Marchi's model, and seepage times are shortened if the undisturbed water table is higher. This is an important issue to be considered when dealing with the seepage vulnerability of levees, since the position of the undisturbed water table is usually unknown and can lead a well-designed levee to fail unexpectedly.

\section{Definition of the vulnerability index $i_{\text {seep }}$}

A vulnerability index $i_{\text {seep }}$ for the seepage mechanism is defined here as the ratio $\Delta T / T_{\mathrm{cr}}$ where $\Delta T$ is the hydrological time scale for the persistence of river flood level and $T_{\text {cr }}$ is the critical time for the emergence of the phreatic line along the land levee slope.

The critical time $T_{\text {cr }}$ is analytically determined using Eqns (1) and (2) as the minimum time given by the two models, which can be simplified into closed-form expressions.

The critical time for the first model $T_{\mathrm{cr}, 1}$ is directly derived from Eqn (1) by imposing the position of the undisturbed water table. As a first approximation, the phreatic water table can reasonably be assumed to lie between the thalweg of the river cross-section and the protected side elevation. Then, the critical time $T_{\mathrm{cr}, 1}$ always refers to the emergence of the phreatic line at the toe of the landside slope and may be calculated as:
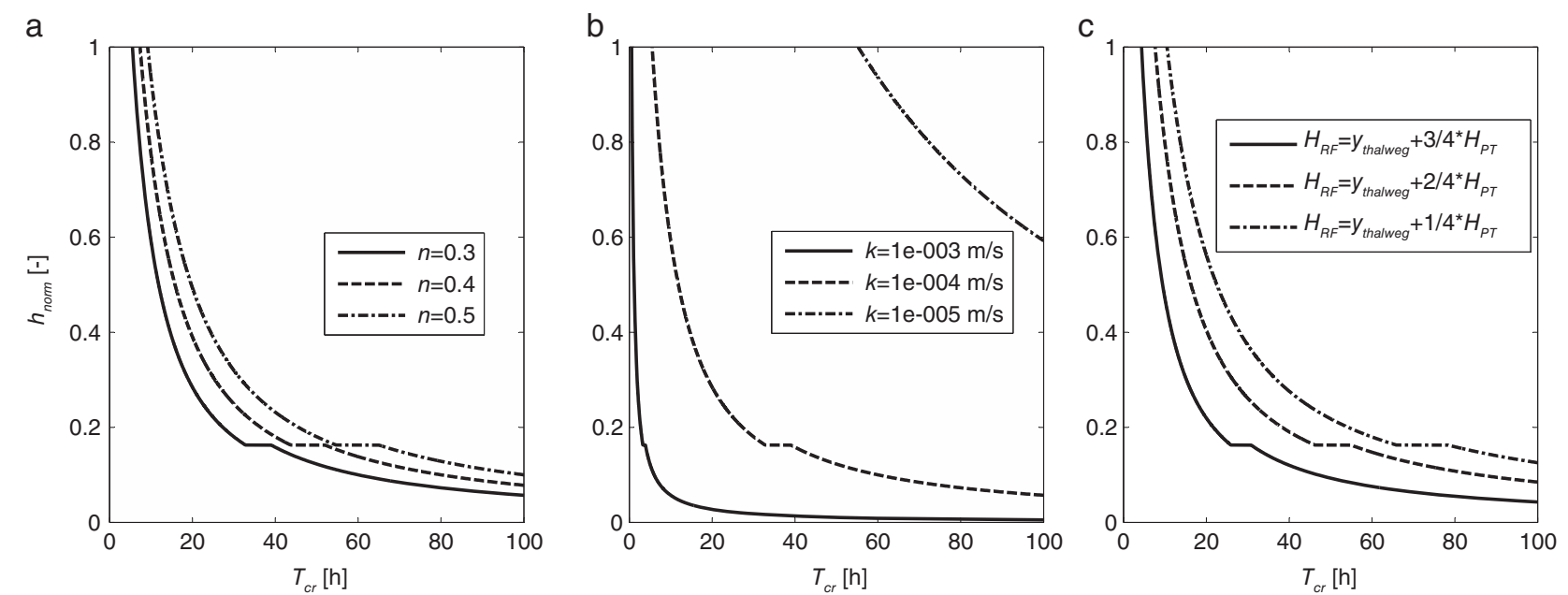

Figure 7 Sensitivity of the critical curve to model parameters: porosity $n$ (a), hydraulic conductivity $k$ (b) and undisturbed water table level $H_{\mathrm{RF}}$ (c) (adopted parameters are: $n=0.3$ for Figure $7(\mathrm{~b})$ and (c); $k=10^{-4} \mathrm{~m} / \mathrm{s}$ for Figure 7 (a) and (c); $H_{\mathrm{RF}}=y_{\text {thalweg }}+2 / 3 \cdot H_{\mathrm{PT}}$ for Figure 7(a) and (b) where $H_{\mathrm{PT}}$ is defined in Figures 3 and 4). 
$T_{\mathrm{cr}, 1}=\tan \left(\frac{\pi}{2} \cdot \frac{H_{\mathrm{PF}}}{h_{0}+H_{\mathrm{RF}}}\right) \cdot \frac{n \cdot L}{k}$

where $H_{\mathrm{PF}}$ is the elevation of the protected side over the undisturbed water table.

On the other hand, the critical time according to the second model $T_{\mathrm{cr}, 2}$ depends on the elevation $y$. An explicit formulation for $T_{\mathrm{cr}, 2}$ may be obtained by imposing the condition that the seepage path $x_{\mathrm{GA}}$ reaches the landside slope in Eqn (2):

$T_{2}(y)=\frac{\left(b_{1} y+b_{2}\right)^{2}}{h_{0}-y} \cdot \frac{n}{2 k}$

where $b_{1}$ and $b_{2}$ are parameters that describe the horizontal length of the seepage path (see Figure 4 ) and depend on the zone where the minimum seepage time is sought after:

$$
\begin{aligned}
& b_{1}=\left\{\begin{array}{c}
-(\operatorname{ctg} \alpha+\operatorname{ctg} \beta), \text { for } 0 \leq y \leq H_{\mathrm{LR}} \\
-(\operatorname{ctg} \gamma+\operatorname{ctg} \beta), \text { for }-H_{\mathrm{RF}} \leq y \leq 0
\end{array}\right. \\
& b_{2}=\left\{\begin{array}{c}
x_{\mathrm{P} 7}-x_{\mathrm{P} 3}, \text { for } 0 \leq y \leq H_{\mathrm{LR}} \\
x_{\mathrm{P} 7}-x_{\mathrm{P} 2}, \text { for }-H_{\mathrm{RF}} \leq y \leq 0
\end{array}\right.
\end{aligned}
$$

The function $T_{2}(y)$ has the following minimum according to the flood level and the levee geometry:

$\frac{\mathrm{d} T_{2}(y)}{\mathrm{d} y}=0 \Rightarrow T_{\mathrm{cr}, 2}=-2 b_{1} \cdot\left(b_{1} \cdot h_{0}+b_{2}\right) \cdot \frac{n}{k}$

The final critical time is then chosen as $T_{\mathrm{cr}}=\min \left(T_{\mathrm{cr}, 1}\right.$; $\left.T_{\mathrm{cr}, 2}\right)$ and is a function of water level $h_{0}$, levee geometry and geotechnical properties $k, n$.

The hydrological time scale $\Delta T$ can generally be referred to as the persistence of the flood levels around the peak for a given hydrological scenario. In the present methodology, $\Delta T$ is defined as the duration of water levels above $90 \%$ of the maximum level of the hydrograph.

Larger values of the vulnerability index $i_{\text {seep }}$ are associated with larger values of the ratio $\Delta T / T_{\mathrm{cr}}$, since, in such cases, the phreatic line crosses the levee body in a time interval shorter than the persistence of the flood hydrograph. Finally, the proposed classification of the vulnerability index is given in Table 1.

The vulnerability index $i_{\text {seep }}$ is estimated here by considering the variability of both its numerator (i.e. $\Delta T$ ) and denominator (i.e. $T_{\mathrm{cr}}$ ), while the geotechnical properties are

Table 1 Vulnerability classification based on the index $i_{\text {seep }}$

\begin{tabular}{ll}
\hline$i_{\text {seep }}=\Delta T / T_{\text {cr }}$ & Vulnerability class \\
\hline$<0.5$ & Low \\
$0.5-1$ & Medium \\
$\geq 1$ & High \\
\hline
\end{tabular}

assumed to be constant. In particular, two different scenarios are here taken into account: scenario A, in which different levee geometries (i.e. different $T_{\mathrm{cr}}$ ) are analysed under given hydrological persistence $\Delta T$ and river water level $h_{0}$; scenario $B$, where different hydrological loads in terms of $\Delta T$ and $h_{0}$ are investigated for a given levee geometry and its critical time $T_{\mathrm{cr}}$.

While this approach cannot provide a comprehensive picture of the whole variability that can occur in real cases it does, however, allow the relative importance of different factors on seepage vulnerability to be ascertained.

\section{Application of the methodology to the Ombrone Pistoiese levees}

The present methodology for the assessment of seepage vulnerability is now applied to the levees of the river Ombrone Pistoiese (Tuscany, Italy) in a reach about $8 \mathrm{~km}$ long from the town of 'Poggio a Caiano' as far as the confluence with the Arno river. The catchment area is about $350 \mathrm{~km}^{2}$.

Due to the lack of knowledge about both the geotechnical properties of the river levees and the position of the undisturbed water table all over the investigated reach, a predefined set of the parameters $n, k$ and $H_{\mathrm{RF}}$ was chosen on the basis of data available in a few river sections. In scenario $\mathrm{A}$, this set of parameters was maintained constant in all the cross-sections as well as the hydrological load, using a conceptual model based on the geo-morphological instantaneous unit hydrograph (GIUH). A return period of $T r=100$ years was imposed which produced a water level at the levee crest and a persistence $\Delta T=14 \mathrm{~h}$ (see hydrograph in Figure 8

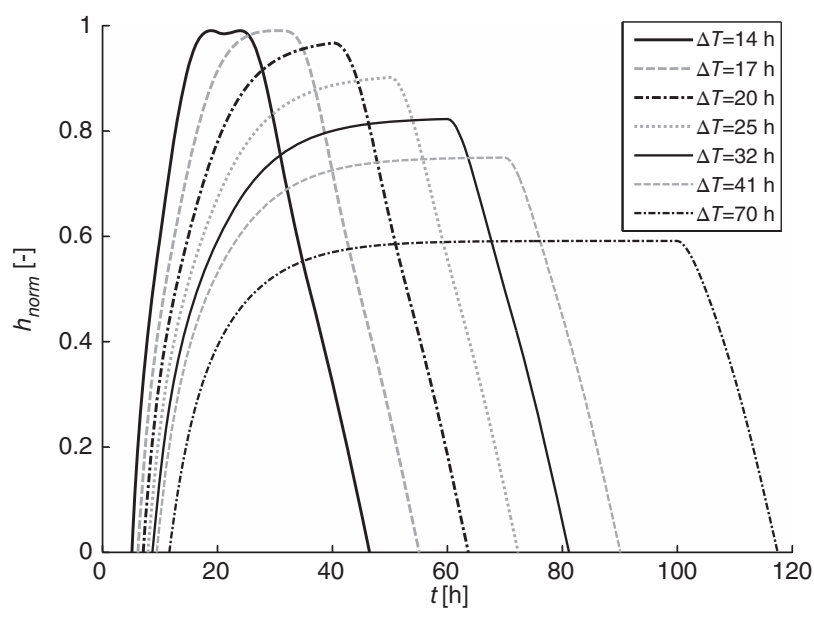

Figure 8 Hydrographs at the Ombrone Pistoiese levees for a return period $T r=100$ years and different durations: $\Delta T$ is the persistence of water level above $90 \%$ of the maximum for each hydrograph. 


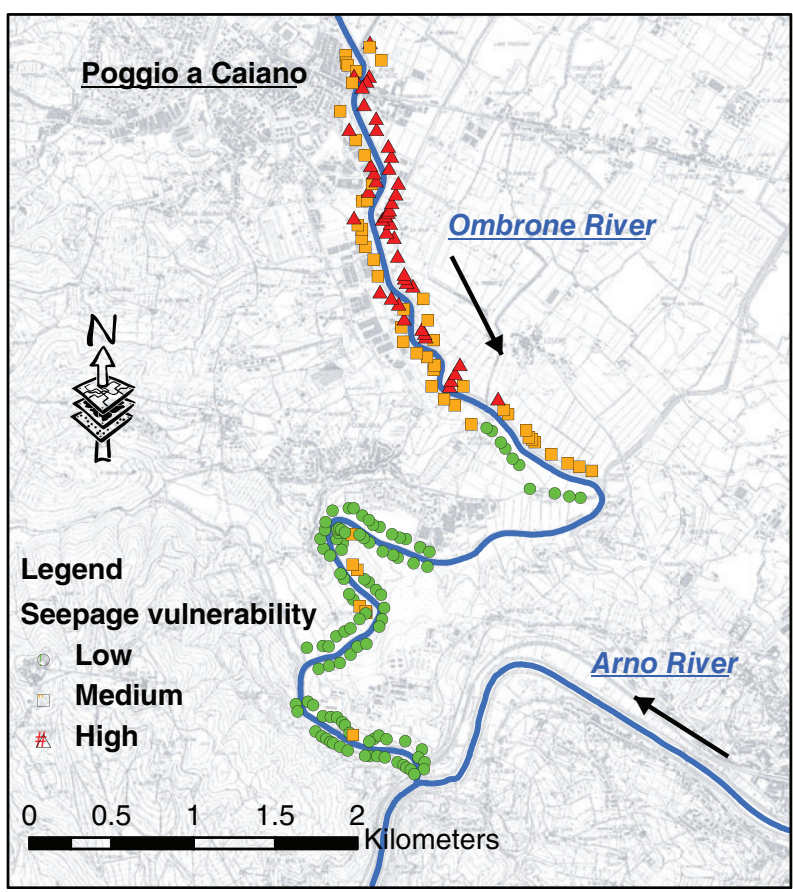

Figure 9 Seepage-hazard map of the Ombrone Pistoiese levees according to scenario $A$ and for a given hydrological scenario ( $T r=100$ years, $\Delta T=14 \mathrm{~h}, n=0.3, k=10^{-4} \mathrm{~m} / \mathrm{s}, H_{\mathrm{RF}}=y_{\text {thalweg }}+$ 2/3. $\left.H_{\mathrm{PT}}\right)$.

marked ' $\Delta T=14 \mathrm{~h}$ '). Therefore, the vulnerability analysis was conducted for the same conditions along the entire river reach. In such a way, this scenario provides the relative vulnerability between the selected levees and thus makes it possible to assess which levees are relatively more prone to fail due to the seepage induced by a given hydrological load. According to this, each river cross-section was elaborated in order to define the coordinates of the characteristic points $\mathrm{P}_{1}-\mathrm{P}_{6}$, for both left and right levees, and the critical time $T_{\text {cr }}$ and the vulnerability index $i_{\text {seep }}$ were calculated.

Results in Figure 9 show that the levees in the upper reach fall into the vulnerability classes 'medium' and 'high' (see Table 1), whereas most of the levees in the downstream reach fall into the 'low' vulnerability class. This variability is due to the different geometry of the river levees and, mainly, to the elevation of the protected land with respect to the levee crest; in particular those in the upper reach have an average height on the land side of about 5 and $3 \mathrm{~m}$ on the left and right side, respectively, whereas the levees in the downstream reach have a height of only about $0.5 \mathrm{~m}$ over the land side.

According to scenario $\mathrm{B}$, different hydrological persistence $\Delta T$ and water level $h_{0}$ have been considered for the typical levee geometry of Figure 5. In this case, for the imposed return period of 100 years, seven rainfall events with different durations have been considered as shown in Figure 8. In such a way, the implications of different combinations of flood peaks and persistence are analysed on the vulnerability index $i_{\text {seep }}$.

This scenario allows one to define the most critical hydrological load for the levee section under investigation. Figure 10 shows the comparison between the critical curve and the water level persistence. It can be seen that for $k=10^{-4} \mathrm{~m} / \mathrm{s}$ the levee conditions are all within the failure zone (see Figure 10a), that is, $\Delta T>T_{\text {cr }}$ even for the lower water levels.

In order to demonstrate the sensitivity to the hydraulic conductivity, the critical curve for $k \approx 2 \cdot 10^{-5} \mathrm{~m} / \mathrm{s}$ is also
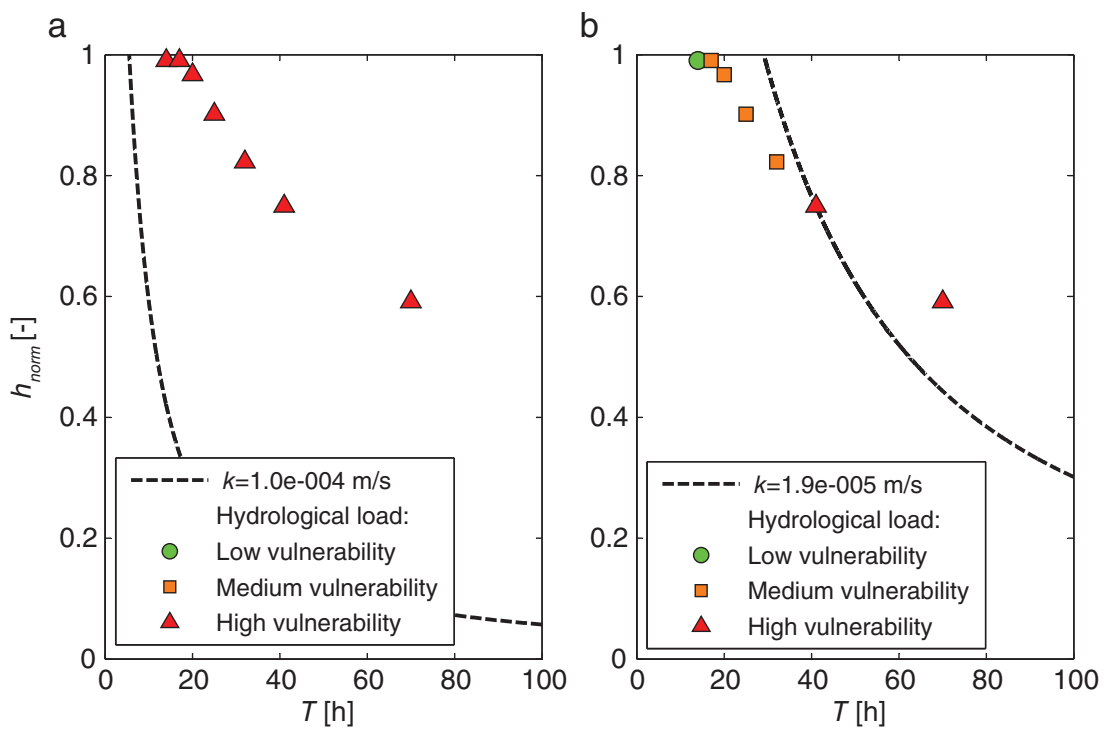

Figure 10 Seepage-hazard analysis for a typical levee according to scenario $B$ with different hydrological loads. The adopted parameters are: $n=0.3, H_{\mathrm{RF}}=y_{\text {thalweg }}+2 / 3 \cdot H_{\mathrm{PT}}, k=10^{-4} \mathrm{~m} / \mathrm{s}(\mathrm{a})$ and $k=1.9 \cdot 10^{-5} \mathrm{~m} / \mathrm{s}(\mathrm{b})$. 
shown (see Figure 10b). In this case, it should be noted that critical conditions are only produced by the longest hydrographs with a persistence $\Delta T>40 \mathrm{~h}$, and for lower water levels.

\section{Conclusions}

In this paper, a methodology for assessing relative earthen levee vulnerability to through-seepage process is proposed. The methodology is based on a comparison between two time scales: one associated with a seepage condition that can typically represent a critical situation for the levee reliability, and the other to the hydrological persistence of the river flood level. The reference condition for the seepage critical time scale was chosen as related to the emergence of the phreatic line on the landside of the levee slope, this situation being preparatory for successive internal erosion mechanisms such as piping. Seepage flow inside the levee is solved by considering two analytical models accounting for the critical condition (i.e. the emergence of the phreatic line) both at the levee toe and at higher elevations towards the levee crest. For each levee, a critical curve can be determined defining the minimum time (or critical time) for the emergence of the phreatic line on the land levee side associated with a given river water level. This critical time is compared with the hydrological persistence of the given water level: when the critical time appears shorter than the hydrological persistence, the levee is classified as highly vulnerable to a seepage failure that can lead to successive structural failure and to the breaching of the levee body.

The methodology can easily be applied to long river reaches as the critical time, in the case of trapezoidal levee cross-section, can be obtained analytically. When geotechnical parameters and the elevation of the undisturbed water table are unknown, the analysis provides an assessment of a relative vulnerability of the levee bodies to through-seepage processes. The methodology was applied to the river Ombrone Pistoiese (Tuscany, Italy) for the definition of seepage-hazard maps.

Moreover, the analysis has pointed out that a levee geometry characterised by a given critical time may show a high vulnerability towards lower water levels associated with those hydrographs with higher volumes and longer persistencies.

These maps, together with overtopping-hazard maps and historical information on levee breaches, provide a fundamental guidance for flood-risk assessment and for maintenance operations, monitoring and surveillance during flood events.

Future developments will include the definition of the vulnerability index and of the seepage-hazard maps considering the most critical conditions arising from the possible combinations of the relevant physical factors (in terms of hydrological loads, levee geometry and geotechnical properties); also, the use of numerical models could provide better results than the analytical ones, being more flexible to cope with actual geometries and non-homogenous geotechnical properties.

\section{References}

Barbetta S., Camici S., Maccioni P. \& Moramarco T. National Levee Database: monitoring, vulnerability assessment and management in Italy. Proceedings of EGU General Assembly 2015, 17, EGU2015-EGU10170.

Bogdanowicz E., Strupczewski W.G., Kochanek K. \& Markiewicz I. Flood Risk for Embanked Rivers. J Geosci Env Protect 2014, 2014, (2), 135-143. doi: 10.4236/gep.2014.23018.

Bonanni G., Carli A., Casarosa N., Ceragioli N., Dell'Aiuto S. Della Maggesa M., Forti M., Matteoni S., Panocchia A. \& Sardi L. La rotta arginale del Serchio a Malaventre (frazione di Nodica) nel giorno di Natale 2009. Il Geologo 2010, 79, 4-19 (in Italian).

Camici S., Barbetta S. \& Moramarco T. Levee body vulnerability to seepage: the case study of the levee failure along the Foenna stream on 1st January 2006 (central Italy). J Flood Risk Manag 2015. doi: 10.1111/jfr3.12137.

CIRIA, Ministry of Ecology \& USACE The international levee handbook. CIRIA, London, 2013.

Cosanti B., Squeglia N. \& Lo Presti D.C. Indagini geotecniche e analisi di stabilità degli argini del fiume Serchio dopo l'alluvione del Dicembre 2009. Proceedings of IARG 2011, Torino (in Italian), 2011.

Fell R. \& Wan C.F. Methods for estimating the probability of failure of embankment dams by internal erosion and piping in the foundation and from embankment to foundation. The University of New South Wales, 2005.

Foster M.A., Fell R. \& Spannangle M. The statistics of embankment dam failures and accidents. Can Geotech J 2000, 37, (5), 1000-1024.

Fox G.A., Wilson G.V., Periketi R.K. \& Cullum R.F. Sediment transport model for seepage erosion of streambank sediment. J Hydrol Eng 2006, 11, (6), 603-611.

Green W.H. \& Ampt G.A. Studies on soil physics, 1: the flow of air and water through soils. J Agric Sci 1911, 4, 1-24.

Guha-Sapir D., Below R. \& Hoyois, P. EM-DAT: International Disaster Database, 2014. http://www.emdat.be/database (accessed 10 January 2015).

Horlacher H.B., Bielagk U. \& Heyer T. Analyse der Deichbrüche an der Elbe und Mulde während des Hochwassers 2002 im Bereich Sachsen. Research report 2005/09, Institut für Wasserbau und Technische Hydromechanik, Technische Universität Dresden, 2005, 82.

Loat R. Flood mapping in Europe - EXCIMAP. UNECE workshop on transboundary flood risk management, Geneva, 2009.

Marchi E. Un criterio per la verifica alla filtrazione delle arginature in terra (A methodology to assess filtration flow inside 
earthen river levees). Giornale del Genio Civile 1957, 6, 1-10 (in Italian).

Marchi E. Sulla filtrazione attraverso gli argini fluviali. Proceedings of VII Convegno di Idraulica e Costruzioni Idrauliche, Palermo, 1961 (in Italian).

Mazzoleni M., Bacchi B., Barontini S., Di Baldassarre G., Pilotti M. \& Ranzi R. Flooding hazard mapping in floodplain areas affected by piping breaches in the Po River, Italy. $J$ Hydrol Eng 2014, 19, (4), 717-731.

Mohamed M.A.A., Samuels P.G., Morris M.W. \& Ghataora G.S. Improving the accuracy of prediction of breach formation through embankment dams and flood embankments. Proceedings of the International Conference On Fluvial Hydraulics, Louvain-la-Neuve, Belgium, 3-6 September, 2002.

Morris M., Dyer M. \& Smith P. Management of flood embankments. A good practice review. Defra/Environment Agency, 2007.

Nagy L. Estimating Dike Breach Length from Historical Data. Period Polytech Ser Civ Eng 2006, 90, (2), 125-139.

Nagy L. \& Tòth S. Detailed Technical Report on the collation and analysis of dike breach data with regards to formation process and location factors. Technical Report, H-EURAqua Ltd., Hungary, 2005.

Nardi L., Rinaldi M. \& Solari L. An experimental investigation on mass failures occurring in a riverbank composed of sandy gravel. Geomorphology 2012, 163-164, 56-69. doi: 10.1016/j. geomorph.2011.08.006.

Ozkan S. Analytical study on flood induced seepage under river levees. PhD Thesis. Louisiana State University, 2003.

Pistocchi A., Zani O. \& Donati F. Sul calcolo dei tempi di saturazione delle arginature. Proceedings of XXIX IDRA Congress, Trento (Italy) 2004, 3, 457-461 (in Italian).

Saucier C., Howard I.L. \& Tom J.G. Levee breach geometries and algorithms to simulate breach closure. SERRI Report 70015001, US Department of Homeland Security Science and Technology Directorate, 2009.

Sherard J.L., Woodward R.J., Gizienski S.F. \& Clevenger W.A. Earth and earth-rock dams, engineering problems of design and construction. New York, NY: John Wiley and Sons, Inc., 1963.

Staiano T., Rinaldi M. \& Paris E. Seepage and stability analysis of embankments during flood events. Proceedings of XXIX IAHR Congress, 16-21 September 2001, Beijing, China.

Van Zyl D. \& Harr M.E. Seepage erosion analysis of structures. Proceedings of the Tenth International Conference on Soil Mechanics and Foundation Engineering, 15-19 June 1981, Stockholm, Part I. The Netherlands: A.A. Balkema Publishers, 1981, 503-509.

Vorogushyn S., Merz B. \& Apel H. Development of dike fragility curves for piping and micro-instability breach mechanisms. Nat Hazards Earth Syst Sci 2009, 9, 1383-1401. 